Check for updates

Cite this: RSC Adv., 2019, 9, 39684

Received 24th October 2019

Accepted 26th November 2019

DOI: $10.1039 / \mathrm{c} 9 \mathrm{ra} 08742 \mathrm{~g}$

rsc.li/rsc-advances

\section{Microwave-assisted synthesis of 7-azaindoles via iron-catalyzed cyclization of an o-haloaromatic amine with terminal alkynes $\dagger$}

\author{
Yi Le, ${ }^{\text {abc }}$ Zhisong Yang, ${ }^{\mathrm{b}}$ Yumei Chen, ${ }^{\mathrm{b}}$ Dongmei Chen, ${ }^{\mathrm{b}}$ Longjia Yan, (D)*bc \\ Zhenchao Wang ${ }^{b c}$ and Guiping Ouyang*abc
}

An efficient and practical procedure was developed to prepare 7-azaindole, starting from an ohaloaromatic amine and corresponding terminal alkynes under microwave irradiation and the scope was demonstrated with a number of examples. The valuable features of this procedure included the ironcatalyzed cyclization, short reaction times and convenient operation. Furthermore, iron catalysis is an interesting alternative to homogeneous catalysis for the synthesis of heterocycles.

\section{Introduction}

In the recent years, microwave (MW) irradiation in synthetic organic chemistry has attracted considerable practical and theoretical attention as a very effective and non-polluting method of activation. ${ }^{1}$ Microwave irradiation often helps to reduce reaction times, minimize side products, increase yields and improve reproducibility. Therefore, the technique of microwave-assisted organic synthesis has been widely and successfully employed in dipolar cycloadditions, ${ }^{2}$ transition metal-catalyzed cross-coupling reactions ${ }^{3}$ and polymer formation. ${ }^{4}$

$1 H$-Pyrrolo[2,3-b]pyridines, often referred to as 7-azaindoles, are bioisosteres of the indole scaffold have been used in diverse areas such as materials and medicinal chemistry due to their physicochemical and pharmacological properties. ${ }^{5}$ For example, the natural product Variolin $\mathrm{B}^{5}$ in Fig. 1 isolated from an extremely rare antarctic sponge is a promising anti-cancer agent. PLX5622 in Fig. $1{ }^{6}$ a brain pentrant CSF1R inhibitor has been used in Alzheimer's disease (AD). Recently, the 7azaindole derivatives were also shown potential anti-cancer activity, including AZD6738 a potent and selective ATR kinase inhibitor ${ }^{7}$ and GSK1070916 an aurora kinase inhibitor. ${ }^{8}$ Thus, development of synthetic methods to access these 7-azaindoles is of great importance to the drug discovery community. ${ }^{9}$

${ }^{a}$ State Key Laboratory Breeding Base of Green Pesticide and Agricultural Bioengineering, Key Laboratory of Green Pesticide and Agricultural Bioengineering, Ministry of Education, State-Local Joint Laboratory for Comprehensive Utilization of Biomass, Center for Research and Development of Fine Chemicals, Guizhou University, Guiyang 550025, China

${ }^{b}$ School of Pharmaceutical Sciences, Guizhou University, Guiyang 550025, China. E-mail:ylj1089@163.com; oygp710@163.com

${ }^{c}$ Guizhou Engineering Laboratory for Synthetic Drugs, Guiyang 550025, China

$\dagger$ Electronic supplementary information (ESI) available. See DOI: 10.1039/c9ra08742g
Our group has been focused on metal-catalyzed crosscoupling reactions for the preparation of bioactive heterocycles. ${ }^{10}$ Based on the broad activities of 7 -azaindole, we are interested in developing new strategies to prepare this novel heterocyclic scaffold. In the literature, the common synthetic methods to prepare azaindoles usually start from commercial aminopyridines, followed by Sonogashira alkynylation by subsequent base-mediated cyclization with various base for building up the pyrrole ring. ${ }^{11}$ As shown in Fig. 2 , these methods were always used Pd-catalysts, such as $\mathrm{Pd}\left(\mathrm{PPh}_{3}\right)_{2} \mathrm{Cl}_{2},{ }^{12 a} \mathrm{Pd}_{2}(-$ $\mathrm{dba})_{3}{ }^{12 b}$ and $\mathrm{Pd}-\mathrm{NaY},{ }^{12 c}$ and also have some disadvantages such as the high price of palladium and problem of pollution. Recently, the establishment of new catalytic methods using iron is attractive owing to the low cost, abundance, ready availability, and very low toxicity of iron. ${ }^{13}$ Furthermore, due to the availability of several catalytic cycles, iron catalysis offers a potential for orthogonal selectivity when compared to other metals,
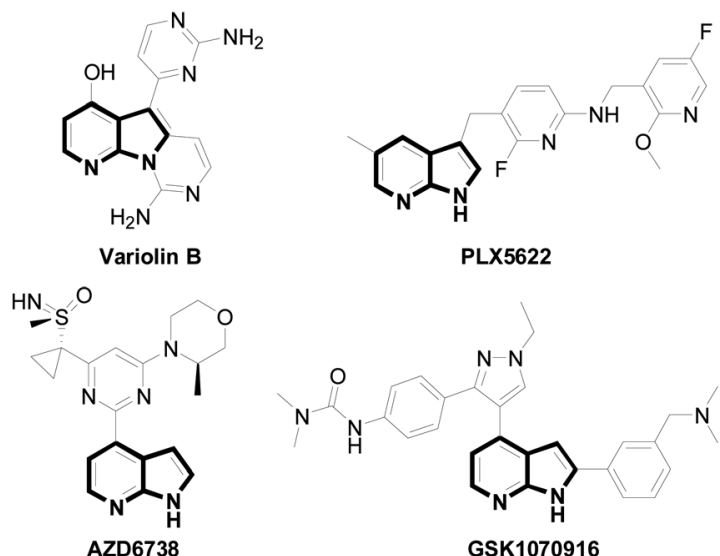

PLX5622

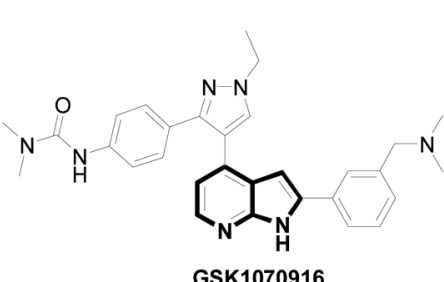

Fig. 1 Bioactive skeletons containing 7-azaindole framework. 


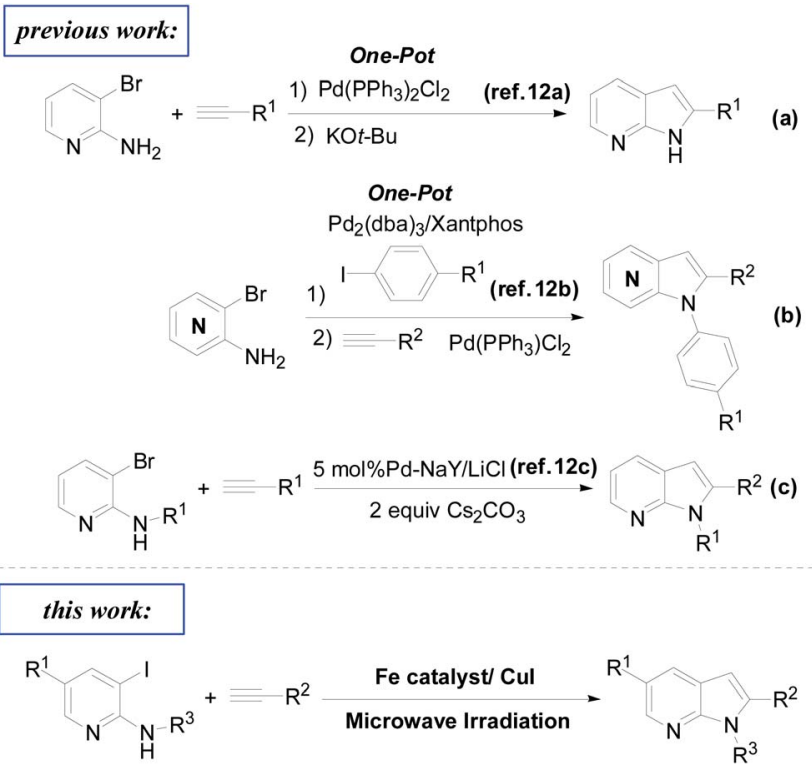

Fig. 2 Different strategies for synthesis of 7-azaindoles.

which allows for streamlined construction of complex molecules by modern cross-coupling chemistry. ${ }^{14}$ Encouraged by the development of iron-catalytic Sonogashira alkynylation ${ }^{15}$ and the microwave-assisted synthesis of indole,${ }^{16}$ we wish to report the iron-catalyzed cyclization of $o$-haloaromatic amine with terminal alkynes under the microwave irradiation.

\section{Results and discussion}

Initially, we chose the commercially available 3-iodo-pyridin-2ylamine 1a and ethynyl-benzene $\mathbf{2 a}$ as model starting materials. We examined the reaction conditions using $10 \%$ $\mathrm{Pd}\left(\mathrm{PPh}_{3}\right)_{2} \mathrm{Cl}_{2}, 10 \%$ CuI, 1.5 equiv. of $\mathrm{K}_{3} \mathrm{PO}_{4}$ in DMF under microwave irradiation of $100{ }^{\circ} \mathrm{C}$, the reaction proceeded for $30 \mathrm{~min}$ and product $3 \mathbf{a}$ was obtained in $12 \%$, which was purified the intermediate $3 \mathbf{a a}$ for $35 \%$ yield (Table 1 , entry 1 ). We subsequently investigated the effect of various catalysts including palladium, silver and iron (Table 1, entries 2-6). Fortunately, we found that $\mathrm{Fe}(\mathrm{acac})_{3}$ was given the best result (Table 1, entry 6). We also tested the amount of CuI, it was no product without $\mathrm{CuI}$ and the similar yield using $20 \% \mathrm{CuI}$ (Table 1, entries 7 and 8). Another blank test was performed only with CuI and shown that 3aa was obtained in $8 \%$ yield (Table 1 , entry 9). It was no reaction at the absence of $\mathrm{Fe}(\mathrm{acac})_{3}$ and $\mathrm{CuI}$ (Table 1, entry 10). Replacement of $\mathrm{K}_{3} \mathrm{PO}_{4}$ by KOAc, or $\mathrm{K}_{2} \mathrm{CO}_{3}$ led to lower yields and $\mathrm{KO}^{t} \mathrm{Bu}$ gave a satisfactory yield (Table 1, entries 11-13). Next, we screened different organic solvents and

Table 1 Optimization of the metal-catalyzed cyclization $3 a^{a}$

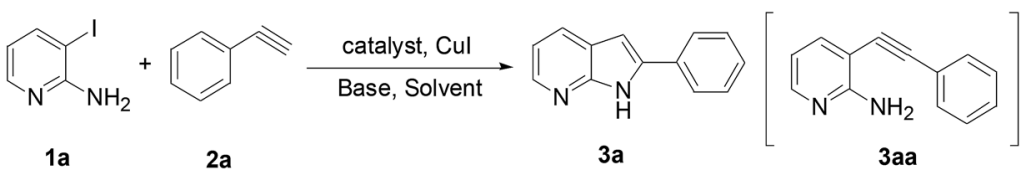

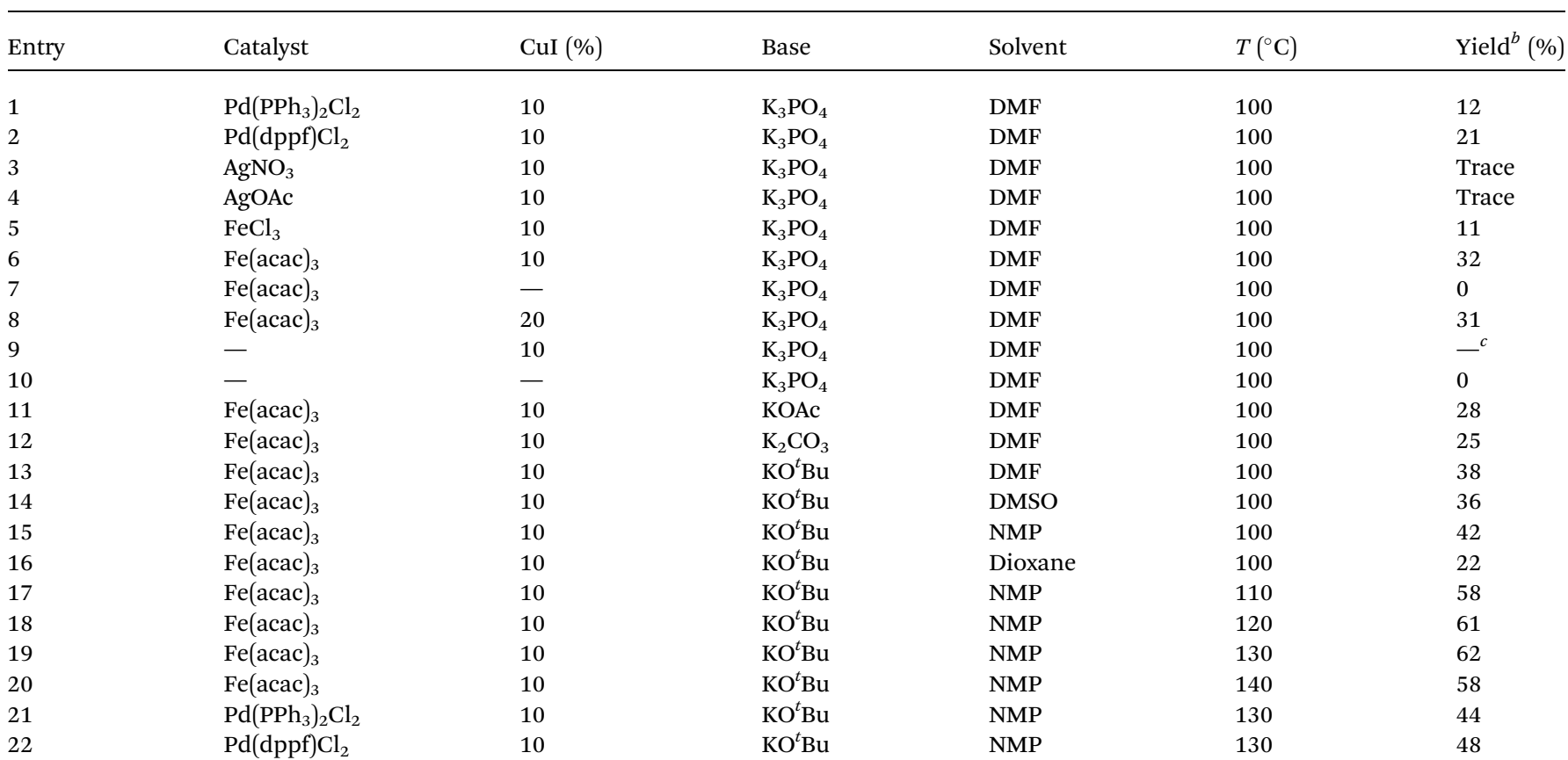

${ }^{a}$ Reagents and conditions: 1a $(1 \mathrm{mmol}), 2 \mathrm{a}(2 \mathrm{mmol})$, catalyst $(0.1 \mathrm{mmol})$, CuI $(0.1 \mathrm{mmol})$, base $(1.5 \mathrm{mmol})$, solvent $(2 \mathrm{~mL}), 30 \mathrm{~min} \mathrm{MW}, 100{ }^{\circ} \mathrm{C}$.

${ }^{b}$ Isolated yields. ${ }^{c}$ Only 3 aa was obtained with $8 \%$ yield. 
identified NMP as the most effective solvent (Table 1, entry 15), while dioxane resulted in a poor yield (Table 1, entry 16). The yield could be further improved by increasing the temperature to a maximum of $130{ }^{\circ} \mathrm{C}$ (Table 1, entry 19), whereas higher temperatures led to partial decomposition (Table 1, entry 20). Interestingly, when we used $\mathrm{Pd}\left(\mathrm{PPh}_{3}\right)_{2} \mathrm{Cl}_{2}$ reported by Mueller ${ }^{12 a}$ or $\mathrm{Pd}(\mathrm{dppf}) \mathrm{Cl}_{2}$ under the optimized condition, the yield was $44 \%$ and $48 \%$, respectively (Table 1 , entries 21 and 22).

In order to optimize the reaction conditions, we speculated that the equivalent of alkyne and microwave time might also be efficient in promoting the microwave-assisted cyclized reaction. After exploring several reaction conditions (Table 2), 3a was obtained in $72 \%$ yield by heating 3 equiv. 2a, 0.1 equiv. $\mathrm{Fe}(\mathrm{acac})_{3}, 0.1$ equiv. CuI, 1.5 equiv. $\mathrm{KO}^{t} \mathrm{Bu}$ in NMP for $60 \mathrm{~min}$ at $130{ }^{\circ} \mathrm{C}$ (Table 2, entry 4). We also tried the reaction under conventional thermal heating condition and the yield of the desired product was 33\% (Table 2, entry 7 ).

Having determined the optimal reaction conditions (Table 2, entry 4), the scope of the reaction was explored with different substituted 3-iodo-pyridin-2-ylamine 1 (Table 3), which were prepared by the reaction of pyridin-2-ylamines with $\mathrm{Ag}_{2} \mathrm{SO}_{4}$ and $\mathrm{I}_{2}$, to afford various 7-azaindoles 3 . As illustrated in Table 3, a variety of substituted 7-azaindoles was readily prepared in good yield through this protocol, and assigned by spectroscopic methods $\left({ }^{1} \mathrm{H}\right.$ NMR and ${ }^{13} \mathrm{C}$ NMR) and HRMS. Both electrondonating group $-\mathrm{CH}_{3}$ (Table 3, entries 3 and 4) and electronwithdrawing group - $\mathrm{CN}$ (Table 3 , entries 5-8) of $\mathrm{R}^{1}$ are tolerated at a variety of positions on the aromatic ring. Alkynes bearing benzene ring such as $4-\mathrm{OCH}_{3}$ and $4-\mathrm{F}$ were also tolerated under reaction conditions as $\mathbf{3 b}$ and $\mathbf{3} \mathbf{d}$ were afforded in $73 \%$ and $68 \%$ yields, respectively. Additionally, aliphatic groups afforded the corresponding products with decreased yields ( $3 \mathbf{h})$. This result was consistent with the observation by Mueller et al. when $\mathrm{Pd}\left(\mathrm{PPh}_{3}\right)_{2} \mathrm{Cl}_{2} /(1-\mathrm{Ad})_{2} \mathrm{PBn}$ was used as catalyst. ${ }^{\mathbf{1 2 a}}$ The introduction of trifluoromethyl group into organic compounds frequently renders remarkable changes in their special size,

Table 2 Optimization of the iron-catalyzed cyclization $3 a^{a}$

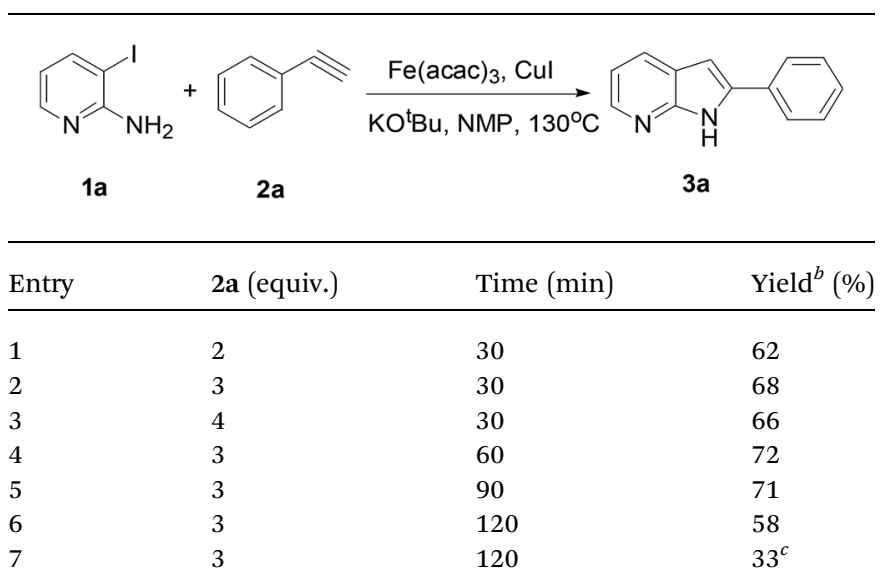

${ }^{a}$ Reagents and conditions: 1a $(1 \mathrm{mmol}), 2 \mathrm{a}, \mathrm{Fe}(\mathrm{acac})_{3}(0.1 \mathrm{mmol}), \mathrm{CuI}$ (0.1 mmol), KO ${ }^{t} \mathrm{Bu}(1.5 \mathrm{mmol}), \mathrm{NMP}(2 \mathrm{~mL}), \mathrm{MW}, 130{ }^{\circ} \mathrm{C} .{ }^{b}$ Isolated yields. ${ }^{c}$ Under conventional thermal heating condition. bioactivity and metabolic stability. ${ }^{17}$ In this paper, we also show such examples of the $\mathrm{CF}_{3}$ substituted 7-azaindoles (Table 3, entries 9-16). We found that the reaction conditions were adaptable with phenyl (3i) and electron-donating substituents at the aryl alkynes, such as methoxy group (3k). In addition to electron-donating substituent, halogens such as $\mathrm{F}$ and $\mathrm{Cl}$ were also tolerated (3j, $\mathbf{3 m}$ and $\mathbf{3 n}$ ). However, aryl groups with an electron deficient substituent led to a lower yield (3l). Additionally, aliphatic groups afforded the corresponding products with reduced yields (3o and $\mathbf{3 p}$ ).

Finally, this procedure was applied to the preparation of 1,2disubstituted 7-azaindoles 5. As shown in Table 4, the Sonogashira and consequently cyclization could be used for preparation the $N$-arylation of azaindoles. The electron-donating groups on the phenyl acetylene, such as $\mathrm{OCH}_{3}(\mathbf{5 c}$ and $\mathbf{5 m})$ were obtained the much higher yield of $78 \%$ than the electronwithdrawing group $\mathrm{F}$ (5b and $\mathbf{5 i}), \mathrm{Cl}(\mathbf{5 d}, \mathbf{5 k}$ and $\mathbf{5 l})$ and $\mathrm{CF}_{3}$ (5e and 5j). 3,3,-Dimethyl-but-1-yne led to 2-tert-butyl-1-(3,4,5trimethoxy-phenyl)-1H-pyrrolo[2,3-b]pyridine $5 f \quad(42 \%)$, the decrease in yield may be due to decomposition of compound 2 under the MW conditions. Interestingly, the ethyl ester substituted group $\mathbf{5 g}$ was also separated with $33 \%$ yield under our MW protocol. In addition to substituted aryl group of $\mathrm{R}^{3}$, the alkyl-substituted compound $\mathbf{4}$ were also compatible with this process, furnishing the desired product $\mathbf{5 n}$ and $\mathbf{5 0}$ in $34 \%$ and $38 \%$ yield.

To investigate the mechanism of this transformation, experiments were carried out. The desired product 3a was

Table 3 Preparation of 7-azaindoles $3 a-p^{a}$

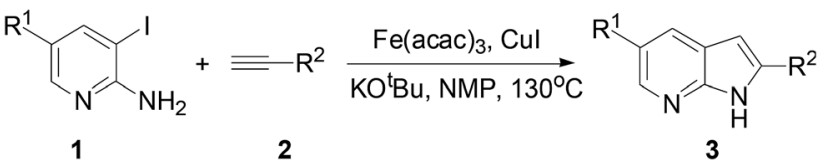

\begin{tabular}{|c|c|c|c|c|}
\hline Entry & $\mathrm{R}_{1}$ & $\mathrm{R}_{2}$ & Product & Yield $^{b}(\%)$ \\
\hline 1 & $\mathrm{H}$ & $\mathrm{Ph}$ & $3 a$ & 72 \\
\hline 2 & $\mathrm{H}$ & $4-\mathrm{OCH}_{3}-\mathrm{Ph}$ & $3 \mathbf{b}$ & 73 \\
\hline 3 & $\mathrm{Me}$ & $\mathrm{Ph}$ & $3 c$ & 73 \\
\hline 4 & $\mathrm{Me}$ & 4-F-Ph & $3 d$ & 68 \\
\hline 5 & $\mathrm{CN}$ & $\mathrm{Ph}$ & $3 e$ & 65 \\
\hline 6 & $\mathrm{CN}$ & 4-F-Ph & $3 f$ & 61 \\
\hline 7 & $\mathrm{CN}$ & $4-\mathrm{OCH}_{3}-\mathrm{Ph}$ & $3 g$ & 66 \\
\hline 8 & $\mathrm{CN}$ & $\mathrm{Me}$ & $3 \mathbf{h}$ & 43 \\
\hline 9 & $\mathrm{CF}_{3}$ & $\mathrm{Ph}$ & $3 \mathbf{i}$ & 62 \\
\hline 10 & $\mathrm{CF}_{3}$ & 4-F-Ph & $3 \mathbf{j}$ & 56 \\
\hline 11 & $\mathrm{CF}_{3}$ & $4-\mathrm{OCH}_{3}-\mathrm{Ph}$ & $3 k$ & 79 \\
\hline 12 & $\mathrm{CF}_{3}$ & $4-\mathrm{CF}_{3}-\mathrm{Ph}$ & 31 & 45 \\
\hline 13 & $\mathrm{CF}_{3}$ & 4-Cl-Ph & $3 m$ & 58 \\
\hline 14 & $\mathrm{CF}_{3}$ & 2-Cl-Ph & $3 n$ & 32 \\
\hline 15 & $\mathrm{CF}_{3}$ & $\mathrm{Me}$ & 30 & 33 \\
\hline 16 & $\mathrm{CF}_{3}$ & $t$-Butyl & $3 p$ & 48 \\
\hline
\end{tabular}

${ }^{a}$ Reagents and conditions: 1 ( $\left.1 \mathrm{mmol}\right), 2$ (3 mmol), Fe(acac) $)_{3}(0.1$ $\mathrm{mmol})$, CuI (0.1 mmol), $\mathrm{KO}^{t} \mathrm{Bu}(1.5 \mathrm{mmol}), \mathrm{NMP}(2 \mathrm{~mL}), 60 \mathrm{~min} \mathrm{MW}$, $130{ }^{\circ} \mathrm{C} .{ }^{b}$ Isolated yields. 
obtained in $70 \%$ yield under standardized reaction conditions (Scheme 1). We also tested the absence of $\mathrm{Fe}(\mathrm{acac})_{3}$ and $\mathrm{CuI}$, it was $22 \%$ yield when $3 \mathrm{aa}$ and $\mathrm{KO}^{t} \mathrm{Bu}$ were used in NMP under MW conditions for $60 \mathrm{~min}$. Base on the observed experimental results and pioneering reports, ${ }^{15,18}$ we have described a plausible mechanistic pathway in Scheme 2. Oxidation addition of $\mathrm{Fe}(\mathrm{acac})_{3}$ by the amine and pyridine functional units resulting in an organoiron complex $\mathbf{A}$. At this stage, trans-metalation by copper complex B provides an intermediate Fe-species C, which could then undergo reductive elimination to forge the new carbon-carbon triple bond, thus yielding the compound 3aa. After furnished the typical Sonogashira coupling, the

Table 4 Preparation of 1,2-disubstituted 7-azaindoles $5 a-m^{a}$

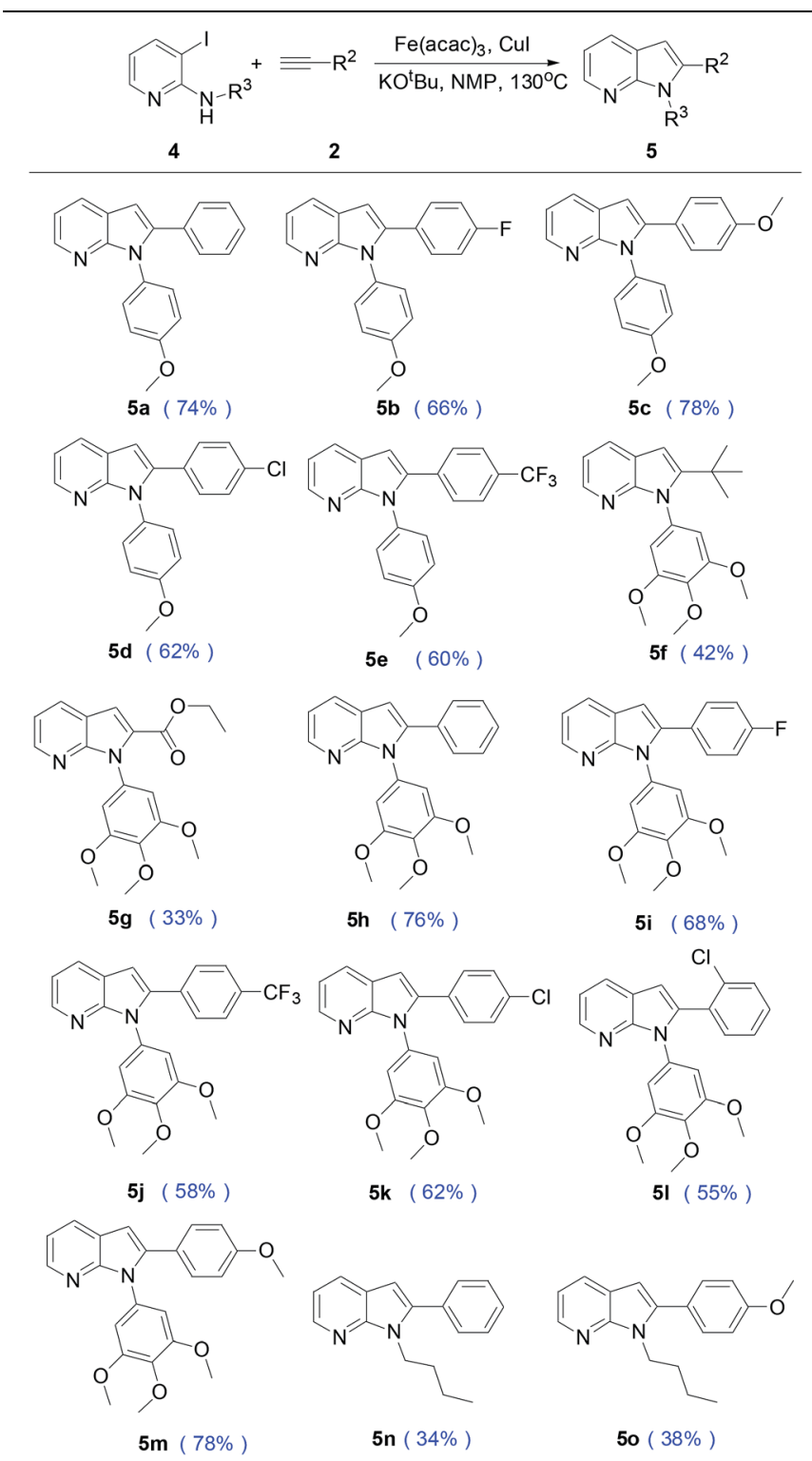

${ }^{a}$ Reagents and conditions: 4 ( $\left.1 \mathrm{mmol}\right), 2$ (3 mmol), Fe(acac) $)_{3}(0.1$ $\mathrm{mmol}), \mathrm{CuI}(0.1 \mathrm{mmol}), \mathrm{KO}^{t} \mathrm{Bu}(1.5 \mathrm{mmol}), \mathrm{NMP}(2 \mathrm{~mL}), 60 \mathrm{~min} \mathrm{MW}$, $130{ }^{\circ} \mathrm{C}$. (a)
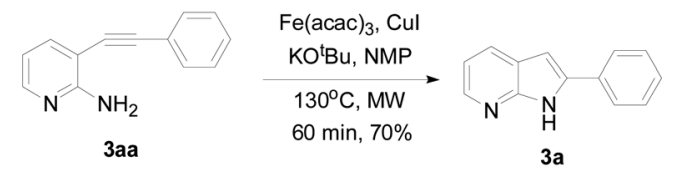

(b)

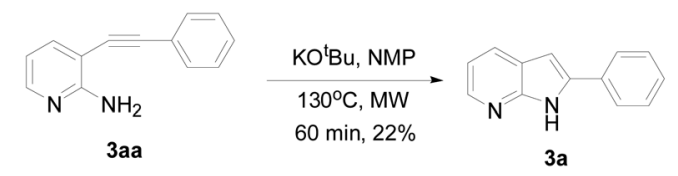

Scheme 1 Complementary experiments.

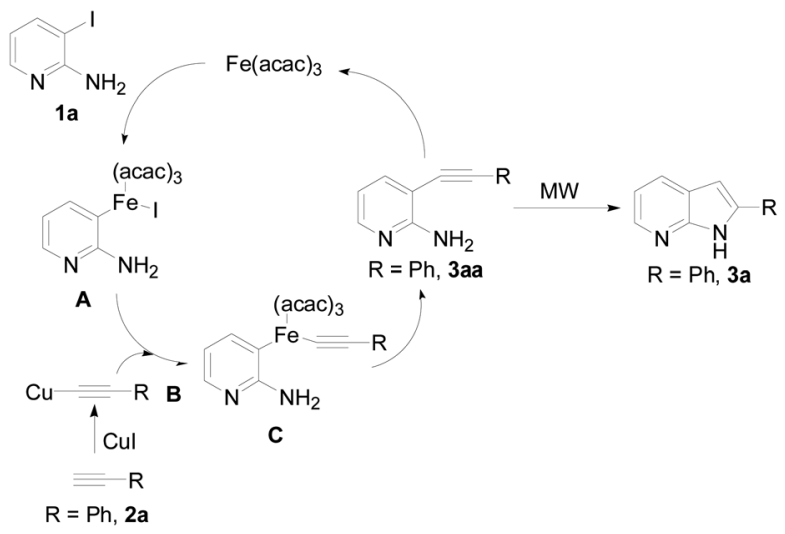

Scheme 2 Proposed mechanism.

desired 7-azaindole was generated under the microwave condition.

\section{Conclusions}

In summary, we have described the synthesis of biologically relevant 7-azaindole ring systems using an iron-catalyzed cyclic reaction under microwave irradiation. This approach provides a rapid and economical access to a diverse range of 7-azaindoles. The method employs readily available reagents and possesses broad scope and good tolerance of functional group, iron catalysis could be an interesting. Further efforts to utilize these compounds as versatile building blocks for assembling interesting heterocyclic molecules which can be applied in medicinal chemistry research are currently underway in our laboratories.

\section{Conflicts of interest}

There are no conflicts to declare.

\section{Acknowledgements}

This project is supported by the National Natural Science Foundation of China (21867004), State Key Laboratory of Functions and Applications of Medicinal Plants (No. FAMP201707K) and (No. FAMP201801K). 


\section{Notes and references}

1 (a) D. Dallinger and C. O. Kappe, Chem. Rev., 2007, 107, 2563; (b) P. Appukkuttan, V. P. Mehta and E. V.-d. Eycken, Chem. Soc. Rev., 2010, 39, 1467; (c) M. Driowya, A. Saber, H. Marzaq, L. Demange, K. Bougrin and R. Benhida, Molecules, 2016, 21, 1032.

2 Z. Yang, J. Wang, L. Peng, X. You and H. Cui, Tetrahedron Lett., 2016, 57, 5219.

3 D. Roy and Y. Uozumi, Adv. Synth. Catal., 2018, 360, 602.

4 M. B. Schuetz, L. Xiao, T. Lehnen, T. Fischer and S. Mathur, Int. Mater. Rev., 2018, 63, 341.

5 S. R. Walker, E. J. Carter, B. C. Huff and J. C. Morris, Chem. Rev., 2009, 109, 3080.

6 E. Spangenberg, P. L. Severson, L. A. Hohsfield, J. Crapser, J. Zhang, E. A. Burton, Y. Zhang, W. Spevak, J. Lin, N. Y. Phan, G. Habets, A. Rymar, G. Tsang, J. Walters, M. Nespi, P. Singh, S. Broome, P. Ibrahim, C. Zhang, G. Bollag, B. L. West and K. N. Green, Nat. Commun., 2019, 10, 3758.

7 R. F. Goundry, K. Dai, M. Gonzalez, D. Legg, A. KearneyMcMullan, J. Morrison, A. Stark, P. Siedlecki, P. Tomlin and J. Yang, Org. Process Res. Dev., 2019, 23, 1333.

8 N. D. Adams, J. L. Adams, J. L. Burgess, A. M. Chaudhari, R. A. Copeland, C. A. Donatelli, D. H. Drewry, K. E. Fisher, T. Hamajima, M. A. Hardwicke, W. F. Huffman, K. K. Koretke-Brown, Z. V. Lai, O. B. McDonald, H. Nakamura, K. A. Newlander, C. A. Oleykowski, C. A. Parrish, D. R. Patrick, R. Plant, M. A. Sarpong, K. Sasaki, S. J. Schmidt, D. J. Silva, D. Sutton, J. Tang, C. S. Thompson, P. J. Tummino, J. Wang, H. Xiang, J. Yang and D. Dhanak, J. Med. Chem., 2010, 53, 3973.

9 (a) S. Zhao and S. Wang, Chem. Soc. Rev., 2010, 39, 3142; (b) W. D. Tap, Z. A. Wainberg, S. P. Anthony, P. N. Ibrahim, C. Zhang, J. H. Healey, B. Chmielowski, A. P. Staddon,
A. L. Cohn, G. I. Shapiro, V. L. Keedy, A. S. Singh, I. Puzanov, E. L. Kwak, A. J. Wagner, D. D. von-Hoff, G. J. Weiss, R. K. Ramanathan, J. Zhang, G. Habets, Y. Zhang, E. A. Burton, G. Visor, L. Sanftner, P. Severson, H. Nguyen, M. J. Kim, A. Marimuthu, G. Tsang, R. Shellooe, C. Gee, B. L. West, P. Hirth, K. Nolop, M. vande-Rijn, H. H. Hsu, C. Peterfy, P. S. Lin, S. Tong-Starksen and G. Bollag, N. Engl. J. Med., 2015, 373, 428; (c) T. Irie and M. Sawa, Chem. Pharm. Bull., 2018, 66, 29; (d) W. Li and L. Dong, Adv. Synth. Catal., 2018, 360, 1104; (e) N. Sharma and Anurag, Mini-Rev. Med. Chem., 2019, 19, 727. 10 (a) L. Yan, H. Wang, Y. Chen, Z. Li and Y. Pei, Mol. Diversity, 2018, 22, 323; (b) L. Yan, M. Deng, A. Chen, Y. Li, W. Zhang, Z. Du, C. Dong, B. Meunier and H. Chen, Tetrahedron Lett., 2019, 60, 1359.

11 F. Popowycz, J. Y. Merour and B. Joseph, Tetrahedron, 2007, 63, 8689.

12 (a) T. Lessing, F. Sterzenbach and T. J. J. Mueller, Synlett, 2015, 26, 1217; (b) S. I. Purificacao, M. J. D. Pires, R. Rippel, A. S. Santos and M. M. B. Marques, Org. Lett., 2017, 19, 5118; (c) E. K. Yum and K. B. Hong, Tetrahedron, 2017, 73, 6581.

13 T. Cernak, K. D. Dykstra, S. Tyaqarajan, P. Vachal and S. W. Krska, Chem. Soc. Rev., 2016, 45, 546.

14 A. Piontek, E. Bisz and M. Szostak, Angew. Chem., Int. Ed. Engl., 2018, 57, 11116.

15 J. Mao, G. Xie, M. Wu, J. Guo and S. Ji, Adv. Synth. Catal., 2008, 350, 2477.

16 A. Carpita, A. Ribecai and P. Stabile, Tetrahedron, 2010, 66, 7169.

17 T. Furuya, A. S. Kamlet and T. Ritter, Nature, 2011, 473, 470. 18 (a) S. Handa, B. Jin, P. P. Bora, Y. Wang, X. Zhang, F. Gallou, J. Reilly and B. H. Lipshutz, ACS Catal., 2019, 9, 2423; (b) K. S. Sindhu, A. P. Thankachan, A. M. Thomas and G. Anilkumar, ChemistrySelect, 2016, 1, 556. 